C.I.F. T. XI, Fasc. 1 y 2 (1985), págs. 9-29

\title{
CONDICIONES AMBIENTALES EN LOS TEATROS DE PLAUTO Y TERENCIO*
}

\author{
José Riquelme Otálora* \\ Universidad de Zaragoza
}

\begin{abstract}
RESUMEN
Tras un breve prólogo en el que trato de explicar los factores que, a mi juicio, determinaron la introducción en Roma de la comedia griega, contrasto, en cada uno de sus diferentes apartados, aquellos aspectos de la personalidad dramática y de la obra de Plauto y Terencio que más discrepan entre ambos autores. Se trata, pues, de un desarrollo comparativo de los puntos más discordantes entre los teatros de uno y otro comediógrafo.

El estudio no responde en la totalidad de sus partes a una línea de investigación personal, ni de descubrimiento de facetas inéditas en la materia tratada. Lo novedoso del trabajo resulta, pues, de la presentación comparada, bajo forma de contrastes, de dicha materia. Creo, pues, que esta modalidad expositiva, aparte ya de su originalidad, puede ayudar a una mejor y más directa apreciación de las diferencias señaladas que he intentado subrayar.
\end{abstract}

\begin{abstract}
The work begins with a brief prologue in which I try to explain the main causes of the introduction of the greec comedy in Rome. Then, I contrast the most opposite dramatic personality aspects in the works of Plauto and Terence. The article is a comparative development of the most opposite points that can be noticed in the theater of both authors.

This study is nor only an original personal investigation, neither a discovery of new aspects of the matter. The originality of this work remains on the comparative exposition of the subject by using a contrastive method, which can be very useful for the study of the differences that I tried to underline.
\end{abstract}

* Doctor en Filología Clásica. Dpto. de Ciencias de la Antigüedad. (Filología Latina); Facultad de Filosofía y Letras; Universidad; 50009 Zaragoza. Recibido el 27-5-1986. 
Desde hace aproximadamente un siglo las nuevas orientaciones de la Historia vienen reprochando a los investigadores y estudiosos de esta ciencia el haberla reducido, hasta entonces, tan solo a príncipes y batallas sin haber tenido en cuenta para nada al verdadero actor protagonista que la muchedumbre popular ha sido, esto es, los esclavos, artesanos, labradores, publicanos y comerciantes. Y es precisamente este reproche el que en nuestros días ha llevado al profesor García Calvo, entre otros, a sostener la tesis de que, al prescindir de la dinámica social de las clases populares, las batallas y los príncipes no pasan de formar, dentro del cuadro general del hecho histórico, un frívolo anecdotario ${ }^{1}$.

Partiendo de esta consideración el mencionado profesor llega a afirmar que "...la comedia romana es con mucho, por lo que al mundo antiguo toca, el más rico documento de esa historia no escrita..." ya que viene a ser "el arte destinado a dotar de facciones a los seres sin rostro de las calles y casas en tanto que se olvida hasta lo sorprendente de aquella otra historia pública que en los aledaños de sus escenarios se representaba"2.

Con esta apreciación conviene de algún modo el juicio de Terencio cuando indirectamente declara que la vida misma es fuente esencial de inspiración para él y otros autores de comedias:

Quod si personis isdem huic uti non licet, qui magis licet currentem seruom scribere, bonas matronas facere, meretrices malas, parasitum edacem, gloriosum militem, puerum supponi, falli per seruom senem, amare, odisse, suspicari?

$$
\text { Eun. vv. 35-40 }
$$

En consecuencia, un análisis sociológico de la comedia romana permite vislumbrar en ella los tres grados de riqueza en que aparece distribuida la sociedad libre de la época reflejada en este teatro: el primero lo compondrían potentes millonarios, dueños de tierras y fletadores de navíos; el

* Con el presente trabajo no he perseguido otro objetivo que el de ofrecer una exposición en la que, tras un breve prólogo que trata de explicar los factores que determinaron la introducción en Roma de la comedia griega, contrasto, en cada uno de sus diferentes apartados, aquellos aspectos de la personalidad dramática y de la obra de Plauto y Terencio que más discrepan entre ambos autores. Se trata, pues, de un desarrollo comparativo de los puntos más discordantes entre el teatro de uno y otro comediógrafo. No responde el estudio a una línea de investigación personal ni de descubrimiento de facetas inéditas en la materia tratada: tan sólo me limito a plantear el estado de la cuestión que ofrece la bibliografía más común sobre el tema. Lo novedoso del trabajo resulta, pues, de la presentación comparada, bajo forma de contrastes, de dicha materia. Creo, pues, que esta modalidad expositiva, aparte ya de su originalidad, puede ayudar a una mejor y más directa apreciación de las diferencias señaladas que intento subrayar.

1. Cfr. A. García Calvo, prólogo a su traducción del Pseudolus de Plauto. "Cuadernos para el diálogo", Madrid, 1971; pág. 5.

2. Cfr. obra citada en la nota 1 , pág. 6 . 
segundo, honradas damas en apuros obligadas a ganarse el pan con la hilatura de sus manos; el tercero, finalmente, antiguos ricos venidos a menos hasta incurrir en la mendicidad y el parasitismo. $\mathrm{ca}^{3}$.

Entre dicha sociedad libre y sus esclavos se desenvuelve la trama cómi-

¿Pero cómo se explica que un género literario como el de la comedia, de ambiente libertino y picaresco por lo general, con sus heteras y siervos, procedente de la Grecia de costumbres corrompidas, se impusiera y triunfara en la austera Roma de los siglos III y II a.C. en la que el puritanismo, la frugalidad y las adustas enseñanzas de Catón el Censor representaban la norma de conducta habitual en los romanos de la época?.

Fundamentalmente tres son las motivaciones que, a mi juicio, pueden dar explicación de la introducción y triunfo en Roma del teatro griego en general:

La primera de estas motivaciones es de orden geográfico: a pesar de la invasión de elementos tradicionalmente considerados itálicos y célticos, desde comienzos del s. IV a.C. en el sur de Italia, en cambio, se mantuvo la influencia griega, sin que ello quiera decir que fuese duradero allí algún poder político griego. En Sicilia y en la Magna Grecia, como en los demás sitios, los griegos no ocuparon nunca más que las costas sin avanzar al interior del territorio. Su poder tenía, pues, límites estrechos. Pero la civilización de estas ciudades griegas del sur fue a menudo brillante; sus riquezas, en algunos momentos, considerables; y, en consecuencia, sus medios de acción grandes. Por ello, aunque el helenismo que allí se desarrolló no pasó de ser en el ámbito político un poder intermitente, por carecer de bases territoriales suficientemente amplias y de una unidad de acción, jugó, sin embargo, en el ámbito cultural un papel predominante, precisamente por lo original de su civilización frente a la herencia de la precedente cultura etrusca que el centro y norte de Italia tenía medianamente asimilada. En consecuencia, los dos siglos que Roma invirtió en establecer su dominación por toda la península itálica, vinieron a coincidir con los de la expansión de la cultura helénica por el mismo radio de acción. Y esta influencia helénica, por la proximidad geográfica del lugar desde donde irradiaba, ya estaba predisponiendo a la admisión por parte de Roma de los géneros de la Literatura griega, entre ellos el dramático en sus diversas modalidades, de las que no puede excluirse la comedia ${ }^{4}$.

La segunda motivación de las tres antes mencionadas que explican la introducción en Roma del teatro griego, es de orden social: la aristocracia que dirigía la política romana en este tiempo poseía una riqueza de base rural; vivía parcamente, sin duda, del cultivo de la tierra. Estos propietarios

3. Cfr. obra citada en la nota 1 , pág. 7.

4. Cfr. A. Meillet. Historia de la lengua latina. "Avesta", Reus, 1973; pp. 65-66. 
rurales poseían la tenacidad, rudeza y espíritu de perseverancia que caracterizan al campesino. Poseían igualmente, como el futuro demostró, un sentido de organización política y la preocupación de un derecho aplicado. Pero carecían, en cambio, de una cultura propia, de especulaciones intelectuales, de refinamiento urbano y, finalmente, de un arte y una literatura propia. $\mathrm{Al}$ lado de esta antigua clase de propietarios rurales, para los que Catón escribe su tratado De Agricultura, se había establecido en Roma una numerosa plebe que no cesaba de aumentar y que iba haciendo su fortuna en el mundo de los negocios. La actividad financiera de esta clase plebeya motivó la infiltración, dentro de su propio seno, de negociantes que, procedentes de la Magna Grecia o de la propia Grecia, le contagiaron algo de su lengua y no poco de su cultura; contagio que provocó el establecimiento en Italia de numerosos artistas griegos. La población antigua se vio así sumergida entre esta gran masa de alógenos y sus descendientes $\mathrm{y}$, a pesar del poder que había conservado, tuvo que sufrir necesariamente la acción de una gran muchedumbre como la que se le había agregado. Cuando se diversifican las tendencias, preferencias y gustos literarios conforme a una población tan heterogénea, el cultivo de los géneros literarios indígenas no puede dejar de ser afectado por otros géneros extraños a ellos, a pesar de lo celosos de sus tradiciones que sean los dueños del país. La civilización griega y, por ende, parte de su literatura se infiltraron entre los comerciantes, marineros y el pueblo de la ciudad de Roma, grupos sociales estos entre los que se acomodaría perfectamente, por la propia naturaleza del género, la comedia griega, denominada, en sus adaptaciones latinas, comedia paliata ${ }^{5}$.

La tercera motivación de las tres a que antes me refería como causantes de la introducción del teatro griego en Roma, es de orden político-bélico: en política exterior e interior las numerosas contiendas que Roma durante este tiempo sostuvo, determinaron que, de una parte, los soldados legionarios que participaban en las campañas guerreras, necesitaran distracción en los ratos de ocio, entre combate y combate. Suministrada esta distracción, entre otras variadas formas, bajo la modalidad de espectáculos teatrales, suponía para dichos soldados una distensión a su actividad militar. En sus más o menos prolongadas estancias en Sicilia y Magna Grecia estos soldados se habían aficionado al teatro griego, y dentro de él a la modalidad de la comedia. A su regreso a Roma, tras las campañas militares, la afición al género que habían adquirido en aquéllas tierras, demandaba el traslado a su ciudad de estas representaciones teatrales, a las que igualmente acabó por aficionarse la plebe, ya compuesta, como antes mencioné, por numerosos emigrantes griegos, predispuestos por su procedencia natural a dar buena acogida al género. Entre este sector social alcanzaron su mayor éxito las comedias de Plauto. De otra parte, también los generales victoriosos, por las mismas causas y en idénticas circunstancias, se habían aficionado al teatro. 
Pero su prosapia aristocrática, así como su mayor grado de cultura y refinamiento adquiridos en la sociedad más erudita que frecuentaban, exigían al género cómico la dignidad y pureza helénica que Terencio supo darle.

Ya examinadas las tres motivaciones que considero fundamentales como causantes de la introducción en Roma del teatro griego, examinaré de pasada los efectos que dicha introducción produjo atendiendo tan solo al ámbito concreto de la comedia, por ser el que en este trabajo precisamente me está ocupando:

Por las tres explicadas motivaciones el tiempo se hizo maduro para la introducción en Roma de la comedia griega. No se había abandonado la antigua uirtus, pero se estaba esfumando la dureza con que se la había practicado al entrar en contacto los romanos con las formas más humanas y flexibles del pensamiento griego. Bien es verdad que oficialmente en Roma seguía sin haber lugar para la vida frívola de Atenas. La comedia paliata con su disipación y su heteras, con su seducción y su adulterio, no podía contar con la aprobación de la vieja nobleza romana. Pero parece indudable que existía en Roma, en el s. II a.C. una disposición para la comprensión, una leve distancia respecto a las exigencias de vida establecidas como norma, una actitud de espíritu reflexiva y tolerante que se imponía, hasta cierto límite, debido al creciente influjo de la cultura griega y al refinamiento cada vez mayor de las formas de vida y del trato social. En este ambiente precisamente describe Cicerón a Lelio como un estoico sin rigor. Es de notar que Terencio aborda dos veces, en Heautontimorumenos y -más explícitamenteen Adelphoe, el problema de la disciplina doméstica; y que las dos veces la dureza anticuada en la educación de los hijos, que hasta entonces había sido habitual en Roma, tiene un efecto contrario al que pretendía alcanzar: Menedemo en Heautontimorumenos ha provocado con su excesiva severidad que marche de casa al extranjero su hijo Clinias; pero cuando el muchacho regresa inesperadamente, el viejo pasa de ese rigor educativo a la indulgencia total ${ }^{6}$. Demeas en Adelphoe educa a uno de sus hijos duramente haciéndole trabajar en las más rigurosas faenas agrícolas; no obstante, el muchacho se extravía en andanzas libertinas ${ }^{7}$; al final de la obra Demeas descubre la conducta licenciosa de su hijo y, disuadido por su hermano Mición de la dureza educativa empleada a causa del nulo efecto que con ella ha obtenido, pasa de un extremo al otro, del rigor máximo que caracterizaba la educación dada por un padre romano del tiempo, a la indulgencia total que anula su autoridad paterna ${ }^{8}$. Y estas actuaciones no eran más que un reflejo en el teatro de la transformación de costumbres que la influencia griega estaba provocando en Roma.
6. Vv. 410-511.
7. Vv. 254-287.
8. Vv. 776-997. 
Dentro de la producción literaria de la antigua Roma, y atendiendo a las comedias conservadas, Plauto y Terencio son los más destacados representantes del género en la vertiente de la paliata ${ }^{9}$.

Coinciden ambos autores en dos puntos: primero, en haberse dedicado exclusivamente a la comedia paliata, frente a la mayoría de dramaturgos que hasta su tiempo también cultivaron la tragedia; y segundo, en haber tomado como modelo los mismos originales, poco más o menos, de la comedia nueva griega.

Por lo demás, numerosas son las diferencias que los separan en toda la gama de aspectos del arte dramático.

$\mathrm{Y}$ son precisamente estas coincidencias y diferencias lo que me ha llevado a tratar conjuntamente en este trabajo las peculiaridades propias del teatro de cada uno de estos autores, con el fin de hacer resaltar, mediante el establecimiento de contrastes, las características más acusadas de ambos teatros, a pesar de su falta de contemporaneidad:

1. Aulo Gelio en 3,3,14 y 17,21,46, -que, por lo demás, no hace sino reproducir noticias tomadas de Varrón-informa de que Plauto, procedente de Sarsina en la Umbría, llegó a Roma a una edad temprana. Y en efecto, buena prueba de ello es el manejo que de la lengua latina hace el comediógrafo: pues no puede haberla aprendido tardíamente; es su propio idioma. Ningún escritor ofrece en mayor grado que él la impresión de una riqueza lingüística espontánea. Muestra, además, en sus modos de expresión un conocimiento literario tan rico que hace pensar en un estudio profundo bajo la dirección de un letrado. ¿Pero en qué condiciones realizó este aprendizaje? ¿Fue, como en el caso de Terencio, en calidad de esclavo ligado a un amo al que también habrían seducido sus cualidades espirituales? Desde luego no parece que Plauto pudiera venir de Sarsina a Roma con grandes recursos. Esta pequeña aldea de la montaña que recomendaba solamente su queso de cabra no debía, en efecto, contar con gruesas fortunas. Pero la suposición de que Plauto viniera a Roma, como Terencio, en calidad de esclavo no pasa de ser una conjetura. Cabe pensar que su padre se desplazara a la Urbe en busca de fortuna cuando el muchacho debía contar muy pocos años. Lo cierto es que, frente a la ambientación distinguida y moralizante del teatro de Terencio, producto de la asociación de éste al círculo aristócrata y helenizante de los Escipiones, la obra de Plauto, de carácter más popular, resulta ser la consecuencia de la vida bohemia y dinámica de su autor. Este, según Aulo Gelio en los pasajes anteriormente aludidos, salido de la infancia, ingresó como actor en una compañía de cómicos y, llegado más tarde a

9. Cronológicamente habría que situar entre Plauto y Terencio, la figura del otro gran comediógrafo latino en la vertiente de la paliata, Cecilio Estacio. Pero de él no puede hacerse ningún tratamiento en especial porque, aparte de los escasos fragmentos conservados de su obra, existen pocas apreciaciones sobre la misma, entre las que merece destacarse la de Varrón: in argumentis Caecilius poscit palmam, in ethesi Terentius, in sermonibus Plautus (menipp. 399 B). 
empresario y director de las representaciones, se puso a escribir comedias imitadas de los modelos griegos de Filemón y Dífilo (pertenecientes a la comedia media); Demófilo, Posidipo y Menandro (pertenecientes a la comedia nueva). Después de haber ganado algún dinero en el teatro se arruinó, al parecer, tratando de hacer fructificar su capital en el comercio marítimo; y habría regresado a Roma en tal estado de pobreza que se vería obligado a colocarse de sirviente de un panadero. Partiendo de esas condiciones probablemente rehizo su fortuna consagrando por completo el último período de su vida a la actividad teatral.

Estas noticias que suministra Aulo Gelio, ciertas o no, muy bien convienen al carácter popular y folklórico del teatro de Plauto; teatro que al parangonarlo con el de los grandes autores de nuestro Siglo de Oro, nos hace pensar, como el de éstos, en el producto de una experiencia variada y fecunda en incidentes, como por las noticias que anteceden parece que fue la de Plauto.

Contrastando con la casi carencia de datos biográficos sobre Plauto, sí disponemos, en cambio, de varias biografías terencianas, de las que la más importante y célebre es la compuesta por Suetonio.

Por ésta y otras biografías es posible saber que la vida de Terencio transcurre entre la Segunda y Tercera Guerra Púnica. Se ignora su nombre originario. Probablemente nacido entre el 190 y 185 a.C. y oriundo de Cartago, parece que llegó muy joven como esclavo a Roma, a la casa del senador Terencio Lucano que, seducido por las cualidades de espíritu del muchacho, le hizo educar esmeradamente y muy pronto le concedió la libertad, y su propio nombre. Sobre las mencionadas cualidades de espíritu que el joven poseía de un modo innato, y la mencionada educación recibida, Terencio adquirió un refinamiento aristócrata que le llevó a asociarse y a tener una buena acogida en el Círculo de los Escipiones, asociación literaria caracterizada por una gran afición a la cultura griega. Ajeno, pues, a los contactos populares, a diferencia de Plauto, compuso una obra dramática de ambientación más distinguida que la de éste e impregnada de un elevado tono moralizante, pero a la vez menos dinámica y sensorial que la de Plauto.

2. Los pocos datos disponibles sobre la bohemia y agitada vida de Plauto bien convienen al tono popular y folklórico de su teatro, como antes mencioné: como organizador de las representaciones, Plauto tendría que pensar en todo y hacer frente a todo; debía ser a la vez, además de escritor, director de compañía, diseñador, contratista, decorador y asumir a un tiempo todas las funciones de las que cada una en el teatro moderno exige un especialista al menos. Para hacer aceptar su obra, era preciso, además, entenderse con los ediles públicos, o con los ricos particulares que organizaban o patrocinaban los juegos y las representaciones. Era preciso igualmente triunfar contra los competidores, imponerse a un público variado, saber agradar a la élite sin descontentar al pueblo. Se comprende, pues, que en esta exitencia agitada Plauto, a diferencia de Terencio, haya tenido poco tiempo para perfeccionar y publicar sus obras. Llevado del ritmo trepidante 
de su vida no debía apenas ocuparse de lo que había escrito la víspera: el hoy y el mañana bastaban para absorberle ${ }^{10}$. Estas circunstancias personales explican el dinamismo patente y sensorial en casi toda su obra, frente a la de Terencio más elaborada y reposada.

Estas noticias sobre Plauto ya sitúan ante el acentuado contraste que sus hechos producen con las circunstancias ambientales que enmarcan la producción dramática de Terencio: en efecto, según la vida relatada por Suetonio, este dramaturgo aparece como el escritor científico que somete su obra a la depuración que le imprime una reflexión pausada y rebosante de documentación y erudición: a) merece resaltarse, ante todo, cómo el joven Terencio, antes de lograr la representación de su primera comedia, Andria, quiso someterla a la previa aprobación de Cecilio Estacio, su inmediato predecesor en el género cómico y en la acentuada tendencia helenizante que, a medida que avanzaba el s. II a.C., dicho género iba adquiriendo en mayor grado. b) En esta misma línea de la escrupulosidad literaria de Terencio también se insertan las propias acusaciones malévolas de Luscio Lanuvino al dramaturgo de que era ayudado en la composición de sus comedias por sus ilustres amigos del Círculo de los Escipiones, Lelio y Escipión, hecho que, de ser cierto, no excluye la verosimilitud de un espíritu de trabajo en Terencio preocupado por el logro de una obra acabada $y$ perfecta, la propia del hombre que se sienta sin prisas para escribirla y que no repara en medios para lograr la culminación del efecto artístico pretendido. c) Otro dato más que corrobora el espíritu científico y reposado del trabajo de Terencio es su viaje de estudios al extranjero al final de su vida; viaje que supone el primer caso conocido de un uso que tendrá varios seguidores en el mismo s. II a.C. y se generalizará en el s.I a.C.. Terencio querría conocer el país de sus modelos, Menandro y Apolodoro de Caristos, asistir en los teatros griegos a las representaciones de actualidad y orientarse en vista de futuros trabajos. Aunque se discute la meta del viaje emprendido, cabe conciliar la diversidad de hipótesis al respecto, pensando que nuestro poeta visitara sucesivamente Grecia y Asia Menor, lugar este último en donde Pérgamo con su célebre biblioteca resultaba ser un centro intelectual de poderosa atracción. d) Es consenso general de todas las biografías terencianas el hecho de que Terencio murió durante el regreso de este viaje; pero la incertidumbre envuelve las circunstancias precisas de su muerte: Cosconio, Varrón y Suetonio le atribuyen haber perecido en el propio naufragio de la nave en que regresaba a Italia. Los demás autores, y entre ellos Porcio Licinio Latrón, dicen que murió en tierra firme tras haberse salvado del naufragio, ya sea en Arcadia, ya en Leucadia, como consecuencia del disgusto que le produjo la pérdida en este naufragio de su equipaje, entre el que contaban nuevos modelos griegos, comedias de Menandro que el dramaturgo traía a Roma como material de trabajo. En la misma línea de la preocupación de Terencio por su trabajo

10. Cfr. A. Ernout. Plautus. Comédies. vol. I (prólogo). "Les Belles Lettres", París, 1932; pp. X-XII. 
artístico habría que incluir su muerte en medio de las circunstancias del disgusto, si es que éstas son ciertas ${ }^{11}$.

3. Los antiguos clasificaban las comedias en motoriae y statariae. Las primeras son de acción movida, las segundas consisten en diálogos. De manera general las de Plauto podrían clasificarse dentro de las motoriae: la única excepción la constituyen los Captiui. Las de Terencio, dentro de las statariae. Donato en su comentario a Terencio observa que sólo el Phormio est prope tota motoria. Por el contrario, Heautontimorumenos, como explica Ambivio Turpión en el $v$. 46 del prólogo, está toda en diálogos: in hac est pura oratio ${ }^{12}$. Por su parte, la crítica moderna, representada por Rostagni, también se inclina a ver en Eunuchus una comedia fértil en incidentes y juegos de escena.

Los prólogos de las comedias de Plauto, contrastando con el tono bullicioso y movido de la obra en sí, son de un aire sereno y tienen como misión única introducir al espectador en la acción de la comedia para un seguimiento más fácil del asunto de la misma. En efecto, Plauto no es el hombre de las confidencias y lamentaciones que hallamos en los prólogos de las comedias de Terencio. No se le ve, como a éste, hacer confesión de sus deberes y deplorar sus infortunios ante la acusación de sus rivales literarios. Hay en Plauto demasiada vida ardiente y apasionada como para dejarse ir a las confesiones, por muy veladas que sean, y a las recriminaciones, que no son otra cosa que muestras de debilidad de carácter.

También contrastando, pero ahora ya en sentido inverso, con el tono reposado y suave de las comedias, resaltan los prólogos de Terencio, especie de sátiras literarias apasionadas, violentas y acerbas en las que Terencio se defiende de sus rivales, que atacaban la autenticidad y legitimidad de la obra. Luscio Lanuvino -según nos informa Donato- le echó en cara la contaminatio de sus obras y el plagio, además de colaboraciones ajenas. La contaminación se refiere a Andria que toma algunos elementos de la Perinthia de Menandro. En el prólogo de Andria Terencio invoca en su apoyo a Nevio, Plauto y Ennio, que también contaminaron, y se defiende en este caso especial apelando a la semejanza de ambas piezas (vv. 5-23). Se lanza la acusación de plagio contra Eunuchus y Adelphoe, entendiéndose aquí por plagio la refundición en la comedia griega básica de otra comedia griega que ya con anterioridad algún otro autor latino había adaptado: en Eunuchus Terencio introdujo un personaje del Adulador de Menandro; personaje que, con anterioridad a Terencio, Plauto ya había introducido en su Colax. Terencio se defiende de este hecho afirmando que no conocía la introducción plautina (vv. 23-24) cosa bastante probable en unos tiempos en que las

11. Cfr. L. Rubio. Terencio. Comedias. vol. I (prólogo). "Alma Mater", Barcelona, 1957; pp. IX-XVII.

12. Cfr. J. Marouzeau. Terence. Comédies. Vol. I (prólogo). "Les Belles Lettres”, parís, 1947; pág. 44. 
comedias sólo circulaban en ejemplares únicos para la escena. En Adelphoe Terencio había introducido una escena de los Synapothnescontes $\alpha$ (unidos en la muerte) de Dífilo, en la que se representa el rapto de una muchacha de un burdel: Plauto había adaptado esta obra de Dífilo en sus Commorientes, pero había omitido la escena en cuestión tomada por Terencio en sus Adelphoe, con lo que este autor dice en el prólogo de esta comedia que Plauto le dejó el campo libre para adaptar la escena con toda legitimidad (vv. 6-14). Es sospechoso, sin embargo, que Terencio conozca o no las adaptaciones plautinas según su conveniencia personal cara a justificarse. En el prólogo a Phormio contesta Terencio a la crítica que Luscio hacía contra su obra en conjunto (vv. 1-21). Pasa al contraataque y le recuerda a su crítico que haría mejor criticándose a sí mismo. En efecto, según nos refiere Terencio en el v.9 y ss. del prólogo de Eunuchus, Luscio Lanuvino, al llevar a las tablas el Tesoro y la Aparición de Menandro, tradujo tan literamente que resultó ininteligible para los romanos; y de otra comedia de Luscio cuyo título no se nombra dice Terencio en el v. 10 del prólogo de Phormio que debió su éxito principalmente a la interpretación. Volcacio Sedígito confirma este juicio, al colocar a Luscio sólo en la categoría inmediatamente superior a un autor sin éxito en la comedia como lo era Ennio; aunque es oportuno añadir que el propio Volcacio, dentro del mismo canon que establece de los comediógrafos latinos, transmitido por Aulo Gelio en 15,24,3, sitúa a Terencio detrás no sólo de Nevio, Plauto y Cecilio, sino incluso de los oscuros Licinio Imbrex y Atilio (poeta durissimus este último, según Cicerón). Acaso era el insultante Luscio el jefe del colegio de autores, por lo que refiere Terencio en el v. 22 y ss. del prólogo de Heautontimorumenos; y logrando menos éxito que Terencio en la comedia, pretendía cerrar el camino con su crítica a los esfuerzos de superación de éste ${ }^{13}$.

Respecto a la cronología de las comedias de los dos autores comparados, los editores modernos han ordenado las de Plauto alfabéticamente, ya que un ordenamiento cronológico, a pesar de las tentativas llevadas a cabo con este propósito por A. de Lorenzi (Cronología ed evoluzione Plautina, Nápoles, 1952), no puede restablecerse con seguridad absoluta. De todas formas, aun suponiendo que pudiera reconstruirse un orden cronológico seguro para las comedias plautinas, cabría preguntarse si nuestro conocimiento de Plauto aumentaría con ello, ya que existe en su obra una unidad tan notable que sería vano apoyarse en la cronología para tratar de descubrir en ella una evolución del pensamiento o estilo de este autor.

Para las seis comedias de Terencio, en cambio, sí ha podido reconstruirse un orden cronológico por sus didascalia, noticia oficial registrada en los archivos que indicaba el autor y el título de la obra, el original griego, la ocasión y la fecha de representación, el dominus gregis o director de la compañía, el actor principal, y el compositor de la música y de los modos

13. Cfr. L. Bieler. Historia de la literatura romana. Versión española de M. Sánchez Gil. "Gredos", Madrid, 1983; pp. 73-74. 
musicales: Andria es la más antigua; está tomada de la Andria y Perinthia de Menandro. Se representó en 166 a.C. tras haber sido sometida por parte de su autor a la previa aprobación de Cecilio. La primera representación de Hecyra, comedia tomada de Apolodoro de Caristos, data del 165 a.C.. Heautontimorumenos, siguiendo a Menandro, se representó en 163 a.C.. Eunuchus, tomada de dos obras de Menandro, fue una de las comedias de más éxito; se representó en 161 a.C., el mismo año que el Phormio: tal es el nombre del parásito que aparece en la obra, tomada de Apolodoro de Caristos. En160 a.C. se representaron los Adelphoe, imitada de Menandro con una escena tomada de Dífilo. El mismo año volvió a representarse por segunda vez Hecyra en las honras fúnebres de L. Emilio Paulo. El mismo año volvió a representarse por vez tercera Hecyra con motivo de los Ludi Romani. El 159 a.C. es el año de la muerte de Terencio: dejó una herencia de veinte hectáreas de tierra y una hija que un caballero romano tomaría después por esposa ${ }^{14}$.

4. Los dos sectores sociales que con exigencias opuestas y cada vez más distanciados componían el auditorio de la comedia en Roma eran: por una parte, el gran público, ignorante e insensible a cuanto no deslumbra materialmente la vista; y por otra, una minoría aristocrática de personajes y literatos de gusto refinado y apasionados por el arte griego.

Plauto se ocupó del primer sector, es decir, de las clases populares. Terencio, del segundo, la élite aristocrática.

En consonancia con estas diferentes clases de público que componen el auditorio de los dos comediógrafos comparados, oportuna se hace aquí una breve alusión a la técnica de composición y al grado de comicidad de cada uno de ellos:

Considerando en primer lugar la técnica de composición eś de notar que:

La acción en Plauto se presenta cargada de vivacidad y sorpresas. El autor no siente la menor preocupación por la regularidad: pasa por alto detalles importantes, explicaciones necesarias, hace aparecer o desaparecer los actores a placer, presenta con brusquedad los desenlaces; alarga con delectación las escenas "rentables", añade otras cuya idea le parece divertida; sólo aspira a llevar a su público de escena en escena. Por este motivo, algunas obras son completamente inorgánicas, como el Poenulus que presenta seguidos e irregularmente desarrollados tres sucesos de los que es víctima el traficante de esclavas, el lenón Lico. Algunas escenas finales, de un movimiento y alegría arrolladores, evocan el Komos $\alpha$ o fiesta llena de desenfreno en que vemos terminar las comedias de Aristófanes: aunque el citado

14. Cfr. obra citada en la nota 13, pp. 72-73; y J. Bayet. Literatura latina. Versión española de A. Espinosa Alarcón. "Ariel", Barcelona, 1985; pág. 100. 
autor griego no fuera su fuente de imitación, el estilo de Plauto resulta muy acorde con el temperamento y sensibilidad de aquél ${ }^{15}$.

De manera contraria, Terencio es un modelo en la técnica de composición dramática por la regularidad y equilibrio con que la desarrolla: sus exposiciones introducen con facilidad y naturalidad en la marcha de la acción. Ya los antiguos supieron apreciarle este mérito. En la Vida de Terencio escrita por Suetonio se dice en el cap. III que Varrón consideraba a Terencio superior a su modelo Menandro en la exposición de Adelphoe y que, por otra parte, al sustituir el monólogo por el diálogo en la exposición de Andria, logra Terencio una variedad y movimiento que no tenía su modelo griego. La intriga, sencilla con frecuencia en los originales griegos, se complica a veces algo en Terencio por la contaminación. En todo caso siempre es interesante y presentada con habilidad. Desaparecen los discursos directos de los actores al público notados en Plauto y las escenas de "efecto" que interrumpen o retrasan la marcha de la acción ${ }^{16}$. dos:

Atendiendo ahora al grado de comicidad de los dos autores compara-

Se hace patente que la alegría y vis comica rebosan en Plauto. Todos sus personajes se encargan de demostrarlo burlándose de sí mismos y del espectáculo, con tal de envolver en su regocijo a los espectadores. A menudo sorprende comprobar como los actores se desprenden de los personajes que representan para hablar en nombre propio, trazar cabriolas o muecas en medio de situaciones emotivas o patéticas: se persigue sólo hacer en extremo divertido el espectáculo, ante el cual nadie puede quedar al margen; y quiere Plauto agradar a todos, ya sea mediante la intervención de "clowns", ya por el placer de invenciones sutiles e inesperadas, ya por los solos o diálogos musicales, conjuntado todo por un gran escritor. Las comedias de Plauto se adaptan a la escena tan perfectamente como sólo suelen hacerlo las escritas por actores (y, según la tradición ya mencionada recogida por Aulo Gelio, él mismo fue actor $)^{17}$.

Por el contrario, en un mundo moderado y distinguido de modales, como el de Terencio, no cabe la risa inmoderada, franca, explosiva e incoercible de Plauto; sólo se admite la sonrisa delicada. Frente a Plauto, para quien todos los recursos humorísticos son pocos, Terencio evita el chiste grosero, las hipérboles divertidas, las expresiones con doble sentido y los neologismos risibles; acude a las situaciones cómicas, pero sin abusar; su norma del ne quid nimis es sagrada también en esto. Lo cómico en Terencio radica esencial y casi exclusivamente en la pintura de caracteres: las inconsecuencias y contrastes de los personajes son, para este autor, el medio más cons-

15. Cfr. la segunda obra citada en la nota 14 , pág. 57.

16. Cfr. obra y lugar citados en la nota 11, pp. XLIII-XLIV.

17. Cfr. la segunda obra citada en la nota 14, pág. 72 . 
tante de excitar la hilaridad del espectador. Pero tal hilaridad, toda ella en "medias tintas" y finas alusiones, pasa fácilmente inadvertida a un auditorio vulgar, y así nos explicamos que haya sido a Terencio tan difícil imponerse a la masa del pueblo, a pesar del prestigioso apoyo que, para la representación de sus comedias, le prestara el actor L. Ambivio Turpión. Desde un principio se echó de menos en Terencio la vis comica que constituyó la cualidad sobresaliente de Plauto y arrastraba siempre a los espectadores ${ }^{18}$.

5. Una presentación pormenorizada de la caracterización de los personajes de la comedia paliata ha sido hecha por A. García Calvo en el prólogo a su traducción del Pseudolus de Plauto ${ }^{19}$. Como complemento a ella, y siguiendo las líneas del estudio comparativo que estoy estableciendo, indicaré seguidamente los diferentes matices psicológicos que Plauto y Terencio imprimen, cada uno por su parte, a un elenco de personajes convencionales cuya constante aparición se hace notar en casi toda la producción cómica de la paliata. Y así pues, siguiendo más o menos de cerca el estudio que sobre este punto hace L. Rubio en el prólogo a su edición de Terencio $^{20}$, destaco que:

Los jóvenes galanes tienen en Terencio las características pasión y fogosidad, propias de la edad, que los emparentan con los personajes análogos plautinos; pero, a diferencia de éstos, corresponden con respeto y afecto a la digna actitud de los padres; actitud ésta que en Plauto brilla por su ausencia. De forma distinta a los plautinos, los jóvenes terencianos se contienen y llegan al arrepentimiento ante la autoridad paterna. En este sentido Quereas en Eunuchus, Pánfilo en Andria y Esquino en Adelphoe son verdaderas creaciones del poeta cómico africano. El parásito en Terencio es algo más que el vulgar hambriento plautino, dispuesto a cualquier humillación por cazar un plato suculento. Los parásitos en Terencio son finos epicúreos que se hacen apreciar por su hábil adulación (caso de Gnatón en Eunuchus) o por su genio inventivo (caso de Formión).

El soldado, aunque tan grotesco en líneas generales como el de Plauto, también sufre algunos cambios en Terencio: Trasón, el soldado fanfarrón de Eunuchus, es un vanidoso, pero sin incurrir jamás en los extremos y ridiculeces del Pirgopolinices de Plauto.

18. Cfr. obra y lugar citados en la nota 11, pp. XLVI-XLVII.

19. Un esquema razonado que compendia las características generales de estos personajes, sin atender a la diferente matización psicológica con que, por una y otra parte, los presentan Plauto y Terencio ha sido trazado por A. García Calvo en la obra citada en la nota 1, pág. 8; y un desarrollo explicado del mismo aparece en las pp. 9-13 de la misma obra. Es interesante la confrontación del esquema y de las explicaciones que le siguen porque, a partir de uno y otras, voy a establecer los diferentes matices psicolögicos a que me estoy refiriendo.

20. Cfr. obra y lugar citados en la nota 11 , pp. XLIV-XLVI. 
El papel de los padres en Plauto (salvo el caso de Hegión en Captiui) ofrece una triste imagen del cabeza de familia en la sociedad romana de entonces: no tienen noción de la responsabilidad que sobre ellos recae en la educación de los hijos; por el contrario, imitan a éstos en sus desordenadas andanzas y, llegado el caso, se benefician de las amantes de sus hijos, como puede verse en Bacchides y Casina; otras veces no quieren que sus hijos vayan a parar a sus propios desórdenes, pero entonces los guía la avaricia y no la noción superior del deber moral. Los padres en Terencio no carecen ciertamente de defectos: han tenido en el pasado, o tienen en el transcurso de la acción, debilidades reprobables, pero conservan el pudor ante sus hijos, cuya vida moral les preocupa hondamente; sus métodos educativos no suelen ser acertados, ya que se muestran demasiado fáciles e indulgentes unas veces, como Mición en Adelphoe; otras, demasiado severos y hasta rudos, como Demeas en la misma obra o Menedemo en Heautontimorumenos; pero jamás pierden la noción básica de su misión educadora, precisamente lo que más falta en el mundo plautino y cuya carencia en éste constituye su mayor depravación.

El lenón tan sólo aparece en dos breves escenas de Terencio y deja de ser repugnante como el de Plauto.

Las matronas, más numerosas en la obra de Terencio que en la de Plauto, a pesar de ser esta última tan superior a la de Terencio en extensión, forman en el comediógrafo africano una agradable colección. El bello sexo encontró en Terencio un abogado poco común en la Literatura. Las matronas en Plauto, excepto Alcmena en Amphitruo, son hurañas, ásperas, altivas, dominantes y derrochadoras. En Terencio todas son delicadas y encantadoras: virtuosas y comprensivas con sus maridos, llenas de ternura para con los hijos y sacrificadas por ellos. Hasta Nausístrata en Phormio, que es rica y caprichosa como sus hermanas plautinas, enfurecida ante la infidelidad de su marido no tarda en sobreponerse a la cólera: se reconcilia con él y usa de su influencia para interceder por cuantos viven a su alrededor.

La doncella, al ser el personaje que menos interviene en el entramado de la obra, juega un papel tan exiguo en ambos autores que su actuación no produce ningún contraste significativo en cuanto al modo de ser tratado por cada uno de ellos.

Los esclavos en I'erencio conservan toda su habilidad e inventiva tradicionales, pero aparecen exentos del cinismo, grosería y desfachatez con que los vemos actuar en Plauto; en Terencio nunca ridiculizan las debilidades de sus amos, a quienes sirven siempre respetuosos y sumisos, con una fidelidad que se eleva a veces hasta el sacrificio; han adquirido cierto decoro y señorío, delicadeza de sentimientos y urbanidad en el trato con sus dueños.

Las mismas cortesanas, que en Plauto son todo egoísmo, avidez, vileza, voluptuosidad y perfidia, aparecen en Terencio adornadas de cualidades notables: son educadas, de finos sentimientos e ideas humanitarias, y sólo un hombre es objeto de sus amores; en medio de la atmósfera viciada que respiran no han degenerado hasta perder el sentimiento de la virtud. 
Ahora bien, según tuve ocasión de estudiar en el trabajo que supuso mi Memoria de Licenciatura ${ }^{21}$, el contraste más significativo entre Plauto y Terencio, dentro del elenco de personajes que vengo enumerando, es el producido por la relación inversa que, en lo que a caracterización y comicidad se refiere, establecen ambos autores entre las figuras de los esclavos y parásitos:

En Plauto, el esclavo se manifiesta como el mayor soporte de la fantasía cómica de la pieza; el parásito, en cambio, asume un papel irrelevante en este sentido. Por el contrario, Terencio invierte las tornas y, si en su obra los esclavos han perdido vis comica frente a sus congéneres plautinos, este efecto ha sido contrarrestado por el desplazamiento del recurso de la comicidad hacia la figura del parásito; desplazamiento que produce una mayor importancia, en relación a Plauto, del papel de este personaje en las comedias terencianas.

Esta observación halla su explicación en la distinta finalidad de la obra de uno y otro autor:

Plauto, afanoso de buscar situaciones cómicas, encuentra en el esclavo el personaje adecuado para tal fin, mientras que del parásito hace, en un plano secundario, un personaje comodín, destinado simplemente a prestar sus servicios a otros a cambio de sabrosos manjares; $y$, aunque su glotonería también origina un efecto cómico, éste es muy inferior, sin embargo, a aquella otra comicidad con que Plauto caracteriza al esclavo.

La obra de Terencio, por el contrario, reviste tonos moralizantes: se ha dicho que el esclavo en ella adquiere una finura de sentimientos, pero este logro conlleva, a su vez, la pérdida de buena parte de la inventiva tradicional del personaje, y en definitiva de la caracterízación cómica de que Plauto lo dotaba.

De forma paralela, el parásito también se refina en Terencio. Sin embargo, este refinamiento del personaje, puesto al servicio de su finalidad de subsistir a costa de los demás, le hace manifestarse, de manera inversa al tratamiento que del mismo personaje hace Plauto, como un pícaro taimado que, con sus tretas y artimañas, absorbe en su actuación la mayor parte de la poca fuerza cómica del comediógrafo africano; absorción que llega al extremo de hacerme afirmar que es el parásito el personaje más cómico de Terencio.

En consecuencia, la proporcionalidad del efecto cómico en las figuras de los esclavos y parásitos del teatro de los dos autores que comparo, puede establecerse, más o menos aproximadamente, del siguiente modo:

21. Este trabajo fue defendido en la Universidad de Salamanca el 27 de junio de 1970 bajo el título Las clases sociales en la comedia paliata: estudio de las figuras de los esclavos y parásitos plautinos y terencianos. 


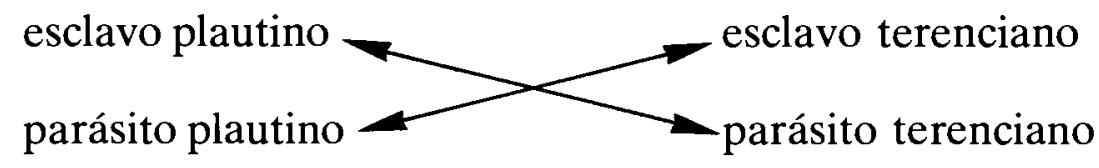

Con lo que resulta que dicha proporcionalidad es completamente inversa entre los cuatro términos establecidos.

Tras estas observaciones sobre el contraste notado en todos los tipos convencionales que comúnmente aparecen en la obra de los dos autores comparados, es posible sostener que todas las clases sociales quedan suavizadas y pulidas en el teatro de Terencio, dramaturgo que muy bien supo trasladar a sus comedias una pintura sin igual de aquella sociedad romana en la que él mismo se movía; sociedad llena de pasiones muy humanas; pero, por otra parte, enamorada de la elegancia, cortesía, distinción y cultura helénicas.

Plauto, en su preocupación básica por hacer reir, carga sus comedias de una fuerza cómica que se desborda en la fantasía y arrastra a los espectadores. A diferencia suya, Terencio, siguiendo más de cerca los modelos de la Comedia nueva griega, está fundamentalmente interesado en presentar sobre la escena una acertada pintura de caracteres, incluso por encima de una intriga mejor o peor articulada. Así supo verlo ya en la propia antigüedad romana el propio Varrón: in argumentis Caecilius poscit palmam, in ethesi Terentius, in sermonibus Plautus (Sat. Menipp. 399 B).

Juicio parecido al de Varrón, aunque de expresión más amplia por los encomios que del dramaturgo africano hace, es el de L. Rubio, cuando en el prólogo a su edición de Terencio comenta, más o menos, que éste tiene el mérito de haber restaurado sobre la escena romana la comedia esencialmente psicológica, que en alguna medida heredó de sus modelos griegos, y de haber penetrado en el alma humana más hondamente que cualquier otro autor antiguo, para ofrecer una viva imagen de la vida real encarnada en el centenar de personajes dibujados en su obra. Por eso, el público inteligente, si echa de menos en Terencio la alegría y la risa franca de Plauto, también ha notado la carencia en Plauto de la cortesía, elegancia y refinamiento de Terencio: pues si Plauto divierte con la acción, Terencio encanta por su profundo estudio de los sentimientos del alma humana ${ }^{22}$.

Estas valoraciones me han llevado a tratar en un trabajo aparte los procedimientos técnicos de que se sirve Terencio para caracterizar moralmente a los personajes de su teatro ${ }^{23}$.

6. El estudio comparativo que estoy llevando a cabo sobre estos dos autores no sería mínimamente completo si no dedicase, como conclusión al

22. Cfr. obra y lugar citados en la nota 11, pp. XLIV-XLVII.

23. J. Riquelme "Técnicas de caracterización moral en los personajes terencianos". Actas del VI Congreso Español de Estudios Clásicos, vol. II, pp. 115-120. 
tratamiento del estilo y calidad literaria de ambos, unas breves consideraciones a la lengua y versificación por ellos manejadas:

Frente a la exuberancia, la vis comica y el vigor de las bulliciosas y picarescas comedias de Plauto, las de Terencio introducen, en consonancia con el ya apuntado carácter de su obra, en un mundo lingüístico más tranquilo y reposado. Los efectos de Terencio son más sutiles que los de Plauto: reserva, reticencia y autocontrol caracterizan su estilo. A estas diferencias lingüísticas de los dos comediógrafos se les viene dando una interpretación social. Según algunos estudiosos corresponden a diferencias de clase, en virtud de las cuales Plauto reflejaría el habla de los estratos más bajos de la población, mientras que Terencio emplearía el lenguaje del Círculo de los Escipiones que frecuentaba, lenguaje identificado con el de la sociedad refinada de su época.

Es evidente que en la lengua de Terencio, como cabía esperar, se han producido ciertos progresos hacia la norma clásica.

Que Terencio utilizó un lenguaje más restringido y refinado que el de Plauto resulta evidente de la consideración de ciertas categorías de palabras que pueden señalarse como típicas del habla coloquial: a lo largo de su obra se aprecia que son utilizados con mayor economía que en Plauto, y como indicadores de carácter, los términos de denuesto o invectiva, que hay menos verbos frecuentativos y compuestos que en Plauto (y la mayoría de los que Terencio acuñó fueron luego incorporados a la lengua clásica), y que, de manera diferente a la obra de Plauto, escasean los diminutivos. También puede notarse cómo en sus pasajes dialogados logra Terencio una más estrecha aproximación al habla natural que la conseguida por Plauto.

Así, se ha hecho ver por Haffter que Terencio, a diferencia de Plauto, prefiere las interjecciones primarias como hem, au, uah, a las secundarias hercle, age de uso mucho más frecuente en Plauto; y que, con más frecuencia que en éste, constituyen, de por sí, en Terencio una expresión completa (por ejemplo, st.! en Plauto aparece siempre seguida de imperativo: st.! tace; st. $a b i$; mientras que en Terencio aparece sola).

Con mucha mayor frecuencia que Plauto, permite Terencio que aparezca un non aislado en una respuesta negativa, supliéndose por la pregunta precedente el verbo que lo apoya. Este es tan solo un ejemplo de la realidad de que en Terencio, en relación a Plauto, hay un más estrecho ensamblaje entre los parlamentos de las partes dialogadas. Los personajes se bastan, como en el habla normal, con el mínimo de palabras, ya que el sentido se completa por el contexto situacional, lográndose así una mayor agilidad y realismo en el diálogo que los notados en Plauto.

Por otra parte, el uso natural de la interrupción se da con una mayor frecuencia en Terencio que en Plauto, quien hace de ella un uso sorprendentemente reducido. Plauto tiende, en efecto, a hacer de cada locución una entidad independiente. También en este aspecto Terencio reproduce con mayor fidelidad que Plauto las condiciones del habla real. 
Terencio, aunque menos vulgar y vigoroso que Plauto, todavía hace uso abundante de expresiones, palabras y giros de sabor coloquial. No hay duda, pues, de que Terencio emplea un notable caudal coloquial que, puede entenderse, refleja el uso idiomático de su tiempo. Fuera éste el modo de hablar usual en el Círculo de los Escipiones o no, en cualquier caso el mayor refinamiento y reticencia de Terencio puede considerarse como característico del habla de una clase elevada, sostiene Hofmann.

Pero las diferencias lingüísticas entre Plauto y Terencio pueden reflejar, en igual medida, -opone Palmer- diferencias de técnica literaria, porque la lengua de Terencio, aunque menos pródiga y descomedida en su empleo de recursos ornamentales, está, lo mismo que la de Plauto, muy alejada del habla cotidiana, incluso de la más educada y culta. Tal puede apreciarse haciendo tan sólo una simple enumeración de pasada de sus principales recursos estilísticos: aliteración, homeoteleuto, anáfora, quiasmo, paralelismo de cláusulas y asonancias, etc... Los pasajes de versos largos muestran, como en el caso de Plauto, una mayor profusión de ornamentación estilística, como el uso de tricola en asíndeton y tricola con anáfora, repetición y miembros crecientes.

Estas consideraciones bastan para mostrar claramente que Terencio empleó los mismos recursos estilístico-convencionales de la lengua literaria arcaica que pueden observarse en Plauto. Aunque sus efectos son más sutiles y su arte más recatado, sigue sosteniendo Palmer que la lengua de Terencio está, como la de Plauto, muy lejos del habla natural, aun de la de cualquier círculo refinado ${ }^{24}$.

La versificación de Plauto también difiere profundamente de la de Terencio.

La antigua comedia latina comprendía una parte dialogada o diverbium, y una parte cantada en la que se distinguía: el canticum sencillo o parte recitada por un actor con acompañamiento musical, y el mutatis modis canticum, en el que el actor se limitaba a hacer los gestos, mientras que un cantor cantaba al son de la flauta. El canticum sencillo era semejante a un aria operística. Se admite comúnmente que al diverbium pertenecen las partes en senarios, que los septenarios troacaicos y yámbicos, así como los octonarios yámbicos, constituyen el canticum sencillo; finalmente, los sistemas de versos variados, como son los octonarios trocaicos, tetrámetros créticos o báquicos, cuaternarios yámbicos completos alternando con cuaternarios yámbicos y trocaicos catalécticos, corresponden al mutatis modis canticum o canto propiamente dicho.

En Plauto las dos terceras partes de la obra están compuestas en los metros propios del canto, frente a una sola compuesta en los metros propios del diálogo. En Terencio, por el contrario, el diálogo predomina sobre el

24. Cfr. L.R. Palmer. Introducción al latín. Versión española de J.J. y J.L. Moralejo. "Planeta", Barcelona, 1974; pp. 96-101. 
canto. Y así puede observarse que las comedias de Plauto eran comedias esencialmente musicales, comedias-ballets; las de Terencio son sencillamente comedias, por el predominio del diálogo y de su medio normal de expresión, el senario. En el terreno de la versificación, como en el de la lengua y el estilo, se aprecia en Terencio menor variedad que en su predecesor Plauto. Este se complace en la polimetría y hace gala de un verdadero fu ego de artificio verbal en las partes líricas. Terencio no puede romper totalmente con la tradición: tiene que hacer concesiones al gusto reinante de insertar en sus comedias partes cantadas, pero es evidente que su propio gusto le lleva a prescindir, en la medida de lo posible, de los elementos líricos; y con esta economía lírica se aproxima más que Plauto a los modelos griegos. Sin embargo, en los metros conservados muestra el poeta africano ser un versificador que conoce todos los recursos del arte y alcanza la más perfecta regularidad $^{25}$.

7. Algunas consideraciones merecen hacerse sobre la repercusión de la obra de los dos autores comparados dentro del ambiente teatral en el que cada uno de ellos se movía:

Plauto, en consonancia con el gusto del público mayoritario cuyas exigencias trata de satisfacer, está exento de preocupaciones históricas y críticas: le importa muy poco ser más o menos fiel a la verdad en la representación del ambiente, funde y confunde lo indígena con lo exótico, lo romano con lo griego, lo real con lo imaginario; da con frecuencia colorido romano a sus piezas griegas insertando en ellas circunstancias y usos romanos: por ejemplo, pone en boca de griegos invocaciones a la Bona Fides, a los Lares, como puede verse en su Curculio y Aulularia; en sus comedias aparecen ediles, centuriones, manípulos, legiones y pretores, aunque la acción se desarrolle en Grecia. También aparecen en boca de sus personajes alusiones al Velabro, al Capitolio, al Lago Curcio y al Foro ${ }^{26}$. De ahí que Plauto satisfaga los gustos y exigencias de su público al insertar en la acción griega costumbres y usos romanos que hacían de sus comedias un teatro vivo puesto que su auditorio se veía reflejado en él. De la fama y éxito de que sus comedias gozaban ante el espectador romano viene a hablar el hecho de que gentes desaprensivas se sirvieron de su nombre para poner en circulación obras propias. Esto provocó que, poco después de la muerte del comediógrafo, circulasen con su nombre hasta ciento treinta comedias, la mayor parte de ellas apócrifas. Afortunadamente, la crítica reaccionó bastante aprisa contra esta invasión y se esforzó por expulsar del Corpus Plautinum los elementos intrusos. Es en Aulo Gelio 3,3,11 donde se nos dice de los filólogos y cartas que hicieron la primera criba. Las tentativas por encontrar la autenticidad plautina desembocaron en la obra de Varrón que utilizando, completando y corrigiendo los trabajos de sus predecesores, pero, sobre todo, interrogando

25. Cfr. obra y lugar citados en la nota 11, pp. XLVIII-L.

26. Cfr. obra y lugar citados en la nota 11, pág. XLII. 
al propio Plauto, sus hábitos, su genio y su estilo, estableció la lista definitiva de las veintiuna comedias que pueden considerarse auténticamente plautinas y que contenía el palimpsesto ambrosiano antes de su mutilación; y si los manuscritos palatinos no conservan trazas de la comedia vigésimo primera, la Vidularia, de la que sólo el manuscrito ambrosiano ha guardado algunos vestigios, es que un accidente material ha privado de sus últimos cuadernos al arquetipo del que derivan ${ }^{27}$.

La huella de Terencio en el ambiente teatral de su época está ligada, de manera contraria a la de Plauto, a las tendencias helenizantes que cada vez más se iban imponiendo en Roma a lo largo del s. II a.C.. Significativos son ya en este sentido los mismos títulos de las comedias: latinos en Plauto, latinos o griegos, e incluso bilingües, en el eslabón intermedio de Cecilio, griegos en Terencio, excepto para el Phormio. Tras la muerte de Plauto, la crítica estética se había vuelto severa y exigía que la pieza griega pasara a la Literatura latina sin desfiguraciones ni mezclas romanas. Terencio se somete en esto al gusto reinante de su tiempo y, por lo mismo, se priva de las referidas libertades plautinas. Todo en sus comedias conserva el cuño griego; incluso, cuando se permite algún ligero cambio del original griego que le sirve de modelo e inventa nuevos personajes, les da nombres griegos y una caracterización adecuada para que la pureza del género no se resienta. Por ello, pese a sus fuentes comunes, medía un abismo entre Plauto y Terencio. De la farsa lírica de Plauto se había pasado al drama psicológico de Terencio. Esta última forma se hallaba más cerca de los originales griegos que la farsa lírica de Plauto, pero al mismo tiempo resultaba menos accesible al público romano de la época: a dicho público se le vio desertar de la primera representación de Hecyra para ir a ver unos funámbulos; y de la segunda representación de la misma obra para ir a ver unos juegos gladiatorios. En efecto, esta comedia es pobre en acción y su delicado tono de conversación requiere una atención concentrada que no podía esperarse entonces de los romanos de aquella época que asistían al teatro: un joven matrimonio aparece desunido. El padre del joven sospecha de su propia esposa que intriga contra su nuera, mientras que en realidad ella no hace sino trabajar por la reconciliación de los cónyuges ${ }^{28}$. La evolución experimentada por la comedia de Plauto a Terencio había sido demasiado rápida y tan sólo respondía al gusto de ciertos círculos aristocráticos. El vulgo abandona una comedia que no está hecha para él. Este es, sin duda, el motivo esencial de la rápida decadencia de la paliata en Roma tras la muerte de Terencio. Como reacción surgirá la comedia togata de ambientación totalmente romana. En consonancia con el gusto reinante el mimo y la pantomima seguirán todavía sobre la escena. Pero la paliata tuvo que buscar tan sólo en las lec-

28. Cfr. obra citada en la nota 13 , pág. 73. 
turas públicas un público mejor dispuesto; y de esta forma pereció como género literario ${ }^{29}$.

Las seis comedias de Terencio nos han llegado a través de los manuscritos Vaticanus, Parisinus, Basilicanus y Ambrosianus ${ }^{30}$.

29. Cfr. obra y lugar citados en la nota 11 , pp. XLII-XLIII.

30. Cfr. obra y lugar citados en la nota 11, pp. LIX-LXIX. 
